\section{俩 Heighten Science P U B L I C I T T I O N S Corporation ISSN 2573-6264}

\title{
Pulsed Shortwave Diathermy and Joint Mobilizations Restore a Twice Fractured Elbow with Metal Implants to Full Range of Motion
}

\author{
David 0. Draper ${ }^{1 *}$ and Emily Veazey ${ }^{2}$ \\ 'David O. Draper, EdD, ATC, FNATA, Professor of Athletic Training/ Sports Medicine, Brigham \\ Young University, RB 106 Provo, UT 84602, USA \\ ${ }^{2}$ Athletic Training Student at Brigham Young University, USA
}

\begin{abstract}
*Address for Correspondence: David O. Draper, EdD, ATC, FNATA, Professor of Athletic Training/ Sports Medicine, Brigham Young University, RB 106 Provo, UT 84602, USA, Tel: 801-422-7866; Email: David_draper@byu.edu

Submitted: 29 December 2016

Approved: 24 January 2017

Published: 27 January 2017

Copyright: @ 2017 Draper DO. This is an open access article distributed under the Creative Commons Attribution License, which permits unrestricted use, distribution, and reproduction in any medium, provided the original work is properly cited.
\end{abstract}

\section{ABSTRACT}

A 21 -y-old recreationally active male lacking the last $30^{\circ}$ of elbow extension from a fractured and dislocated elbow sustained while wakeboarding came to our clinic November of 2015. A regimen was applied of 20-minutes of pulsed shortwave diathermy (PSWD) treatments delivered at 100 watts to heat the affected tissue prior to approximately $40^{\circ} \mathrm{C}$ followed by 10 minutes of joint mobilizations. This was followed by application of an ice pack to the area for 30 minutes. Measurements and treatments were given on Nov 3,5 and 10. The changes in AROM extension were as follows: Nov 3 , from $30^{\circ}$ to $20^{\circ}$; Nov 5 , from $24^{\circ}$ to $10^{\circ}$; Nov 10 , from $10^{\circ}$ to $0^{\circ}$. Over the course of the treatment the PSWD/ joint mobilizations improved extension AROM of the elbow $30^{\circ}$ (full AROM) in just 3 treatments. There was also no post-treatment pain.

\section{INTRODUCTION}

Pulsed shortwave diathermy (PSWD) at 100 watts has been shown to raise the tissue temperature $\sim 4-5^{\circ} \mathrm{C}$ in $15-20$ minutes $[1,2]$. This is appropriate to increase collagen extensibility, inhibit sympathetic activity and lead to an increase in the viscoelastic properties of the tissues $[3,4]$.

When used in conjunction with deep heat, joint mobilizations are capable of increasing collagen extensibility and improving joint physiologic and accessory movements when joint stiffness is present [5-8]. This increase in temperature of the area to be mobilized increases patient comfort during the treatment and minimizes post-treatment soreness [7].

One of the difficult things to do in physical medicine and rehabilitation is to quantify active range of motion (AROM). This varies from person to person and often from author to author. For this paper, AROM was used, relative to entry-level knowledge of goniometric measurement [9-11]. Thus, in this study normal AROM of elbow flexion is listed as being $145^{\circ}$ and normal extension as being $0^{\circ}[11,12]$.

The purpose of this case study was to describe the treatment protocol used in a 21 year old male patient recovering from an elbow fracture/dislocation and a 5 year old fracture discovered upon a recent $\mathrm{x}$-ray. There were no $\mathrm{x}$-rays taken at the completion of the rehabilitation. The significant differences with this injury are three-fold: First, 
there were the effects of 2 fractures to deal with; second, the speed at which the patient regained his range of motion; and third, the use of PSWD and joint mobilizations as the treatment regimen.

\section{CASE DESCRIPTION}

\section{History}

On August $17^{\text {th }}$ of 2015 the patient was wakeboarding on a lake in Utah. He lost control of the wakeboard and fell onto his right arm hyperextending it. The fall resulted in a fracture of his right humerus, a posterior dislocation of the elbow, and a ruptured olecranon bursa (Figure 1). Upon further review of his x-ray, it was determined that he had an old injury (probably from wrestling 5 years earlier). One month later (September $17^{\text {th }}, 2015$ ) the patient underwent open reduction internal fixation (ORIF) of his elbow, with a $12 \mathrm{~cm}$ plate and 8 screws (Figures 2 and 3). He was instructed to wear a brace for 4 weeks; however, he took it off after 10 days. In December he reported our lab with full AROM in elbow flexion and was lacking $30^{\circ}$ AROM in extension (Figure 4)

On the first visit he was asked a series of questions, which included:

- How long has it been since your injury?

- Describe the mechanism of injury.

- Describe any physical therapy or home exercises that you participated in.

- If you were immobilized in a brace or a cast, how many weeks were you immobilized?

- If you are in pain, point to where it hurts?

- Describe the pain (dull, ache, burning, tingling, numb, etc.).

\section{Examination}

The patient reported very little pain at rest, and that he did not engage in any office physical therapy but followed a home program of stretching. AROM in elbow flexion and extension was then measured. He had full flexion AROM $\left(145^{\circ}\right)$ and was lacking the last $30^{\circ}$ of elbow extension. All AROM measurements were obtained using a 10.16 $\mathrm{cm}$ plastic $360^{\circ}$ universal goniometer (scale marked in $1^{\circ}$ increments) for increased validity of the measurements $[10,13-15]$. However, when using a goniometer, validity may range from 4 to $\sim 6^{\circ}$. The ROM was performed as follows:

- Flexion: The patient sat on a low stool so that his upper arm laid flat on a table. The axis of the goniometer was placed over the lateral epicondyle of the humerus. The stationary arm was placed along the midline of the humerus in line with the acromion process of the scapula. The moving arm was placed along

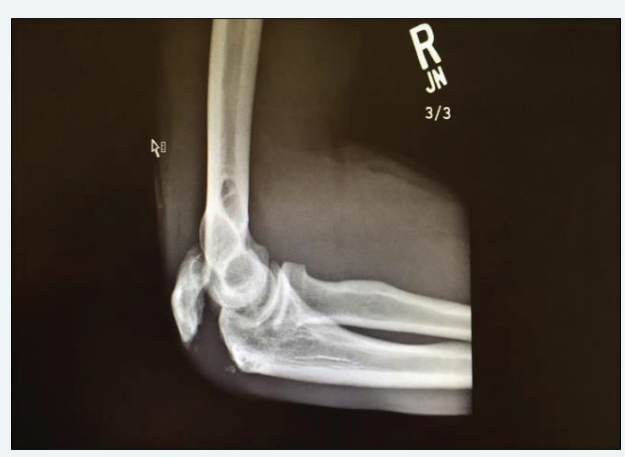

Figure 1: X-ray of fractured elbow. 
the lateral midline of the radius in line with the styloid process of the radius [10]. The patient first performed AROM, then followed this with passive range of motion (PROM).

- Extension. The same landmarks and positioning as were used in flexion were used for extension. The patient performed AROM, followed by passive range of motion PROM [10].

The same goniometer was used for all measurements to limit error due to differences between goniometers. No masking of the goniometer was used during the measurements.

\section{Intervention}

After the AROM measurements, a treatment protocol of PSWD at 400 microseconds pulse duration, 800 pulses per second, 100 watts for 20 minutes was performed (Megapulse II, Accelerated Care Plus, Reno, NV). Immediately after the PSWD treatment, joint traction and mobilizations were performed while the patient was prone. The joint mobilizations consisted of anterior glides of the humerus on the radius and ulna, and proximal radial head glides, for about 10 minutes. Immediately after the joint mobilization, post-treatment AROM, and PROM were recorded. This was concluded with a crushed ice pack for 30 minutes. The purpose of the ice pack was to decrease any pain and prevent secondary hypoxic injury (a condition where swelling of the primary injury might spread into unaffected tissue resulting in secondary injury and more swelling). Also the heat followed by the cold set the joint in plastic elongation from the elastic elongation obtained during the joint mobilizations. During each treatment session, AROM and PROM were measured prior to the PSWD and after the joint mobilizations but before ice pack application. The patient was instructed to refrain from any home exercise program.

During the joint mobilizations, the patient provided feedback on the pain level

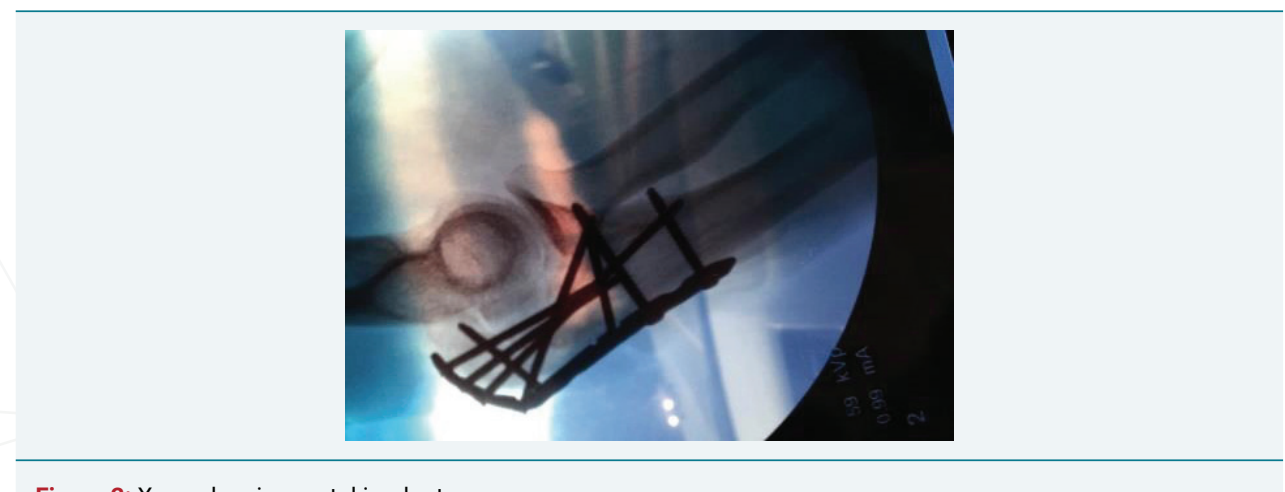

Figure 2: X-ray showing metal implants.

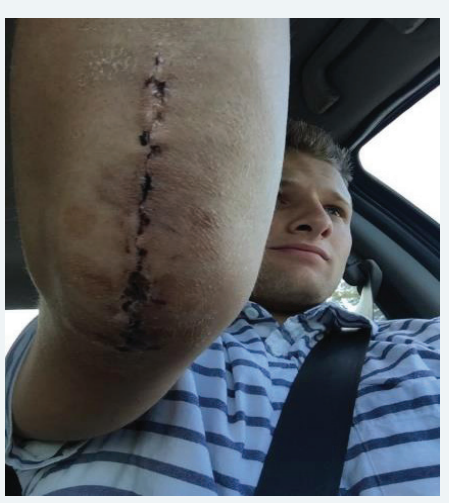

Figure 3: Wound showing the scar. 
of the mobilizations. It was explained that this treatment might be somewhat uncomfortable, but should not result in much pain. This was done to determine if less pressure should be applied. The joint mobilizations used included Maitland grades III: large amplitude movements as long as the resistance was encountered somewhere in that range. Maitland grades IV were also used: small amplitude movement as long as the resistance was encountered somewhere in that range.

\section{RESULTS}

He started at $30^{\circ} \mathrm{AROM}$ in extension and finished at $20^{\circ}$ at the end of treatment 1. He started the second treatment at $24^{\circ} \mathrm{AROM}$ in extension and finished at $10^{\circ}$ at the end of treatment 2 . He started the third treatment at $6^{\circ}$ AROM in extension and finished at $0^{\circ}$ at the end of treatment 3 . Thus, at the end of 3 sessions, the patient achieved full AROM and PROM in extension equal to the unaffected elbow $\left(0^{\circ}\right)$ (Figure 5). He had no pain when he actively flexed and extended his elbow. As mentioned earlier, $\mathrm{x}$-rays were not taken at the end of the rehabilitation. It was felt that this was not needed as achieving full ROM was our goal, and a goniometer provided an objective measure.

\section{DISCUSSION}

The purpose of this case study was to describe the treatment protocol and recovery used in a patient with an elbow fracture/dislocation. This injury and treatment regimen are similar with other injuries where PSWD and joint mobilizations were used to restore ROM [16-19]. However, this is different in that the patient had 2 fractures to deal with, and the speed at which the patient regained his AROM.

Of the dozens of patients, that have had their ROM restored using deep heat and joint mobilizations, this patient's ROM returned the quickest ( 3 treatments). He even had ORIF and still recovered the fastest. The closest of any other patient was
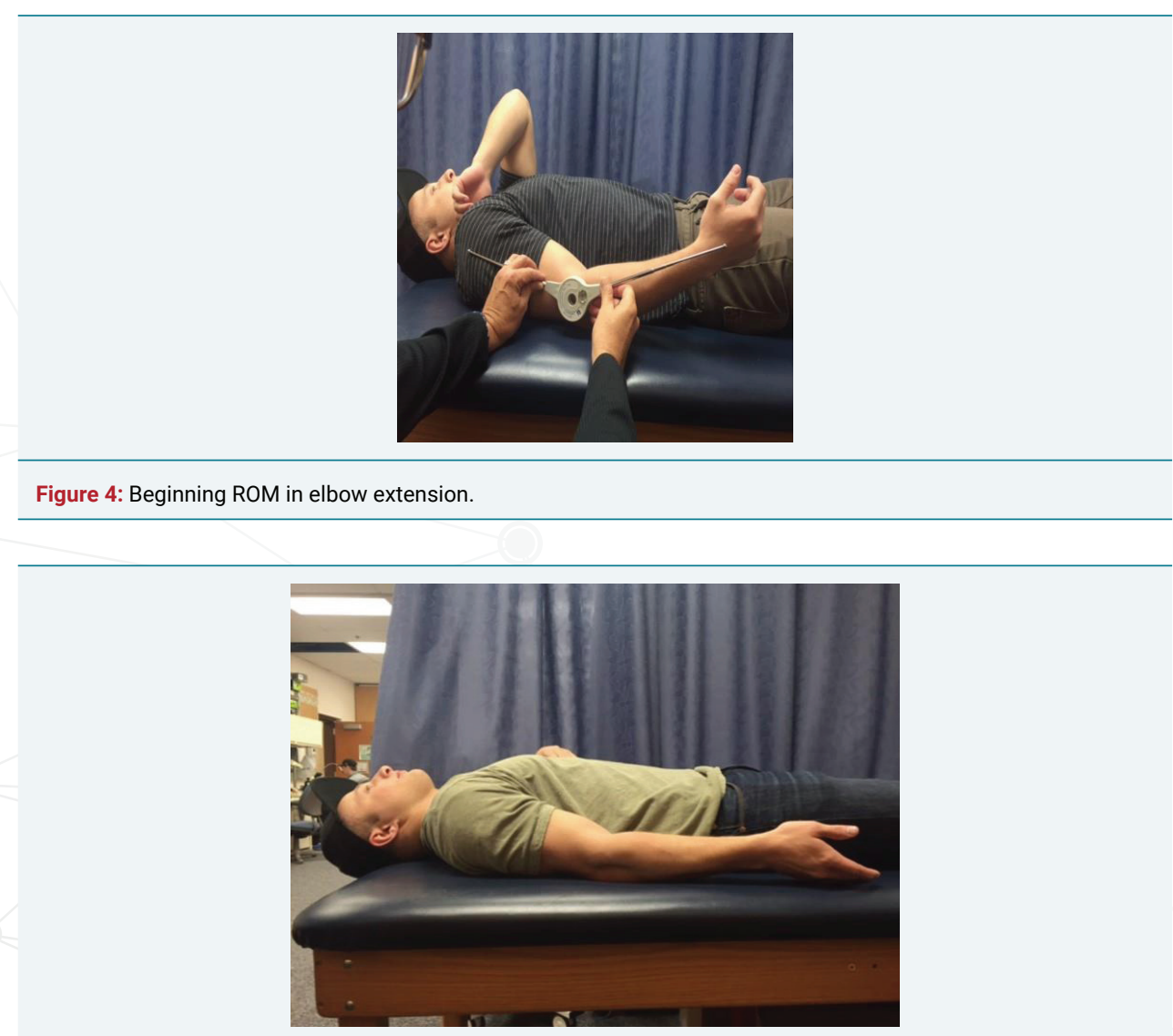

Figure 5: Ending ROM in elbow extension. 
4 treatments [16]. Seiger and Draper restored ROM in a patient who fractured her tibia in an automobile accident [19]. Her ORIF consisted of 2 plates $(1,16 \mathrm{~cm}$ long and the other $8 \mathrm{~cm}$ long with 12 screws). The amount of metal may have led to her long recovery, but her sister had nearly as much metal in the treatment field $18 \mathrm{~cm}$ screw, several screws and plates) and her elbow ROM was restored in 6 treatments [17]. Only due to the amount of ORIF in the joint, the reason the ankle patient wasn't restored to full ROM was probably that she started with less ROM.

Mobilizations to the elbow joint were used because of their effectiveness in improving AROM [5-7]. Joint mobilizations were performed immediately following the application of the PSWD. This is because the heat dissipates fairly rapidly due to the thermal conduction away from the site from the vascular system, although PSWD loses its heat after a treatment slower than ultrasound [20].

Passive stretching was not the main focus because it does not aim at the glide or sliding component that is often missing when a joint has contracted [5-7]. Kaltenborn stated that more ROM will be gained in a hypomobile joint when joint mobilizations are performed than when basic stretching is performed [7]. Stretching only works the angular components (i.e. flexion, extension). Joint mobilization works the assessory components, the most important being slide or glide.

Indications for joint glide mobilization include pain, muscle spasm, guarding, reversible joint hyomobility and functional immobility [5-7]. The indications focused on in this patient were hypomobility, immobility and pain. In order to determine hypomobility, normal and pathologic end feels must be understood. At the elbow joint, normal extension is a "hard" end feel as the olecranon of the ulna comes into contact with the olecranon process. A pathological end feel requiring joint glide mobilizations would be when extension is halted before full extension is reached. The halting would not feel "hard" or like "bone to bone" but it would feel "firm" as if the capsule were tight [20]. At the elbow joint, normal flexion is a "soft" end feel as the biceps brachii comes into contact with the forearm muscles. A pathological end feel requiring joint glide mobilizations would be when flexion is halted before full flexion is reached. The halting would not feel "soft" but it would feel "firm" as if the capsule were tight [20].

In his text," Manual Mobilization of the Joints", Kaltenborn also states that mobilization preceded by heat application often produces greater mobility gains [7], and ice applications after mobilization can better preserve mobility gains. He even lists ultrasound and diathermy as effective deep heat applications.

Collagenous tissue when stressed is fairly rigid, yet when heated it becomes much more yielding [21]. However, the combination of heat and stretch produces a residual lengthening of connective tissue, which increases according to the force applied. The greatest lasting increase in the length of the tissue has occurred when application of a stretch was continued after heating $[22,23]$. This is caused by a reorganization of tissues during the cooling process $[24,25]$. This long lasting or plastic elongation is caused by a separation of adjacent collagen fiber attachments within the connective tissue meshwork [16].

Research has shown that deep heat can be used to treat conditions in which scar tissue has resulted in limited range of motion. However, if deep heat is used before stretching to make scar tissue more pliable, the tissue must be vigorously heated $[4,26]$. When the goal is to increase viscoelastic properties of collagen so tissue can be stretched, or scar tissue reduced, vigorous heating (an increase of at least $4^{\circ} \mathrm{C}$ ) is warranted $[16,27]$.

Years ago research was performed to determine the rate of cooling after thermal PSWD. The temperature at 3 centimeters into the human muscle tissue was raised 
about $4{ }^{\circ} \mathrm{C}$ during PSWD treatment [2]. The average time it took for the temperature to drop to the original baseline was about 20 minutes. Thus, tissue heated by PSWD loses its heat at a fairly rapid rate, but not as fast as ultrasound [20]. Therefore, stretching, friction massage, or joint mobilizations should be initiated immediately after the application of PSWD. The treatment time of $20 \mathrm{~min}$ at $100 \mathrm{Watts}$ total power has been shown to heat tissues $4-5^{\circ} \mathrm{C}$ [2]. This is well within the range for changing viscoelastic properties of collagen [2].

\section{CONCLUSION}

Thermal PSWD used in concert with joint mobilizations is a good regimen aimed at restoring AROM in hypomobile elbows due to injury or immobilization following injury. To determine the full implications of this case study, additional research is needed to determine the effectiveness of this protocol using a greater number of research subjects involved in a randomized experiment with a control group with outcome measures including ROM, pain, edema, and function. Further research methods need to include a blinding of the clinician to the experiment group and of the goniometric measurements.

\section{REFERENCES}

1. Draper DO, Hawkes A, Rigby JH, Johnson W, Eggett D. The Megapulse II SW diathermy device heats muscle tissue higher than the ReBound diathermy device. J Athl Train. 2013; 48: 477-482.

2. Draper DO, Knight K, Fukiwara T, Castel JC. Temperature change in human muscle during and after pulsed short wave diathermy. JOSPT. 1999; 29: 13-22. Ref.: https://goo.gl/8iYjcJ

3. Dyson M. The use of ultrasound in sports physiotherapy. In: Grisogono V, ed. Sports Injuries (International Perspectives in Physiotherapy). 1987; Edinburgh, UK, Churchill Livingstone.

4. Lehmann JF, Masock AJ, Warren CG, Koblanski JN. Effect of therapeutic temperatures on tendon extensibility. Arch Phys Med Rehabil. 1970; 51: 481-487. Ref.: https://goo.gl/Kmks5t

5. Greenman PE. Principles of Manual Medicine $2^{\text {nd }}$ edn. 1996; Baltimore: Williams \& Wilkins.

6. Guler-Uysal F, Kozanoglu E. Comparison of the early response to two methods of rehabilitation in adhesive capsulitis. Swiss Med Wkly. 2004; 134: 353-358. Ref.: https://goo.gl/0N9B69

7. Kaltenborn FM. Manual Mobilization of the Joints - The Kaltenborn Method of Joint Examination and Treatment: Vol 1, $6^{\text {th }}$ edn. 2003; Oslo, Norway, Bokhandel.

8. Maitland GD. Peripheral Manipulation $3^{\text {rd }}$ edn. 1991; Oxford: Butterworth-Heinemann.

9. Magee DJ. Orthopedic Physical Assessment. 1992; Philadelphia, WB Saunders.

10. Norkin CC, White DJ. Measurement of Joint Motion: A Guide to Goniometry $4^{\text {th }}$ ed. 2009; F.A. Davis.

11. Starkey C Ryan J. Evaluation of Orthopedic and Athletic Injuries 3rd edn. 2010; Philadelphia, F.A. Davis,

12. Hoppenfeld S. Physical Examination of the Spine and Extremities. 1976; Norwalk, CT.AppletonCentury-Crofts.

13. Boone DC, Azen SP, Lin C-M, Spence C, Baron C, et al. Reliability of goniometric measurements. Phys Ther.1978; 58: 1355-1360. Ref.: https://goo.gl/Je6z77

14. Gajdosik RL, Bohannon RW. Clinical measurement of range of motion: review of goniometry emphasizing reliability and validity. Phys Ther. 1987; 67:1867-1872. Ref.: https://goo.gl/dmxSwA

15. Low JL. The reliability of joint measurement. Physiotherapy.1976; 62(7):227-229.

16. Draper DO. Pulsed shortwave diathermy and joint mobilizations for achieving normal elbow range of motion after injury or surgery with implanted metal: A Case Series. J Athl Train. 2014; 49: 851855. Ref.: https://goo.gl/3Rsb6S

17. Draper DO, Castel JC, Castel D. Low-Watt Pulsed Shortwave Diathermy and Metal-Plate Fixation of the Elbow. Athletic Therapy Today. 2004; 28-32. Ref.: https://goo.gl/pSJT9q

18. Draper DO, Gage M. Pulsed shortwave diathermy and joint mobilizations for restoring motion in 
a patient with adhesive capsulitis. Athletic Training and Sports Health Care. 2010; 2: 31-35. Ref.: https://goo.gl/stMX6X

19. Seiger C, Draper DO. Use of Pulsed Shortwave Diathermy and Joint Mobilizations to Increase Ankle Range of Motion in the Presence of Surgical Implanted Metal: A Case Series. JOSPT. 2006; 36: 669677. Ref.: https://goo.gl/o4SgWW

20. Cyriax J. Textbook of Orthopaedic Medicine: Diagnosis of Soft Tissue Lesions, $8^{\text {th }}$ edn. 1982; London, Bailliere Tindall.

21. Lehmann JF, Brunner GD, McMillan JA, et al. Comparative study of the efficiency of shortwave, microwave, and ultrasonic diathermy in heating the hip joint. Arch Phys Med Rehabil. 1959; 40: 510-512. Ref.: https://goo.gl/ey2FQc

22. La Ban MM. Collagen tissue: Implications of its response to stress in vitro. Arch Phys Med Rehabil. 1962; 43:461-466. Ref.: https://goo.gl/WDDvOM

23. Lentell G, Hetherington T, Eagan J, Morgan M. The use of thermal agents to influence the effectiveness of a low-load prolonged stretch. J Orthop Sports Phys Ther. 1992; 16: 200-207. Ref.: https://goo.gl/W6Eywh

24. Knight KL. The effects of hypothermia on inflammation and swelling. J Athl Train. 1976; 11: 7-10.

25. Merrick MA. Secondary injury after musculoskeletal trauma: A review and update. J Athl Train. 2002; 37: 209-217. Ref.: https://goo.gl/F4gyGB

26. Lehmann JF, DeLateur BJ. Therapeutic heat, in Lehmann JF: Therapeutic Heat and Cold, $4^{\text {th }}$ edn. 1990; Baltimore, MD, Williams and Wilkins.

27. Knight KL, Draper, DO. Therapeutic Modalities: The Art and Science $2^{\text {nd }}$ edn. 2013; Baltimore, MD, Wolters Kluwer/Lippincott Williams \& Wilkins.

28. Garrett $\mathrm{CL}$, Draper DO, Knight KL. Heat distribution in the lower leg from pulsed short-wave diathermy and ultrasound treatments. J Athl Train. 2000; 35: 50-55. Ref.: https://goo.gl/CC5mSj

29. Draper DO. Injuries restored to ROM using PSWD and mobilizations. Int J Sports Med. 2011; 32: 281-286. Ref.: https://goo.gl/OT1rvO 